\title{
Entrevista
}

\section{CONVERSA COM O EDUCADOR MARCELO ANDRADE ${ }^{1}$}

\author{
Por: Helena Araújoº
}

\begin{abstract}
HELENA ARAÚJO: Qual é o nome da sua pesquisa? Da nossa, eu também trabalho nela. Fale mais um pouco dela: um pouco dosobjetivos, quando começou, qual a proposta, quando vai acabar? E que metodologia será utilizada etc..
\end{abstract}

MARCELO ANDRADE: Vamos lá! Deixa-me ver se eu consigo responder todos, senão você vai me lembrar. A pesquisa está intitulada "Como Preconceitos e discriminações impactam o processo de ensino e aprendizagem? "Senão for isso é muito próximo disso o título cadastrado. Como impactam a aprendizagem ou as aprendizagens. E como subtítulo: "Um estudo longitudinal no Ensino Fundamental". Na verdade, essa pesquisa nasceu de algum acúmulo que a gente vem fazendo no grupo de pesquisa no GECEC, Grupo de Estudos sobre Educação, Cotidiano e Culturas, já há sete anos, o GECEC completa este ano 20 anos sobre a coordenação da professora Vera Candau. Só que desde quando eu entrei no quadro de professor do Departamento de Educação, nós começamos a funcionar como um mesmo grupo, que é o GECEC, com duas equipes; essa equipe que eu coordeno vai fazer oito anos. A gente vem acumulando uma trajetória sobre temas ligados a preconceitos e discriminação no cotidiano escolar, às vezes com as pesquisas específicas dos mestrandos e doutorandos e também, com pesquisas que a gente chama de institucionais, pesquisas que envolvem todo o grupo. Nós tivemos uma primeira pesquisa sobre o referencial de uma autora que se chama Adela Cortina, em que a gente foi ver como os professores e alunos articulam os mínimos acordos éticos para trabalhar os conflitos da pluralidade no cotidiano escolar. Depois a gente avançou tentando entender esses conflitos como referencial da Hanna Arendt sobre o tema da banalidade do mal e de certa maneira essas duas pesquisas institucionais tinham sido desdobramentos da minha tese de doutorado. Pois bem, com esses anos orientando trabaIhos sobre o sexismo ou machismo no cotidiano escolar, a homofobia - entre professores e alunos - o racismo no cotidiano escolar, a intolerância religiosa, temas ligados àquestão da surdez, à deficiência. A gente foi percebendo que, os preconceitos e a discriminação são um problema para a escola, são um problema social, e que inevitavelmente, porque se essa escola está nessa sociedade e não em outra sociedade, a escola brasileira enfrenta isso no seu cotidiano. Depois eu comecei a fazer algumas leituras muito despretensiosas e eu acho que eu tenho muito que aprender ainda, sobre o que a gente chama de estudos longitudinais. Os estudos longitudinais eles tem como características o acompanhamento dos mesmos sujeitos amostrais durante um longo período de tempo. As pesquisas que nós vínhamos fazendo, entrevistam, por exemplo, professores sobre um determinado problema, uma determinada questão e analisamos esses dados. Nos estudos longitudinais a gente analisa isso durante

\footnotetext{
${ }^{1}$ Licenciado em Filosofia, Mestre e Doutor em Educação pela PUC-Rio. Professor do Departamento de Educação da Pontifícia Universidade Católica do Rio de Janeiro (PUC-Rio).

2 Licenciada em História pela UERJ, Mestra em Educação e Doutora em Educação pela PUC-Rio. Professora Adjunta de História do CAp/UERJ, professora de Estagio Supervisionado de História no Departamento de História e do Mestrado Profissional em Ensino de Educação Básica do CAp/UERJ.
} 
e-Mosaicos - Revista Multidisciplinar de Ensino, Pesquisa, Extensão e Cultura do Instituto de Aplicação Fernando Rodrigues da Silveira (CAp-UERJ)

V. 5 - N. 9 - JUNHO 2016 - ISSN: 2316-9303

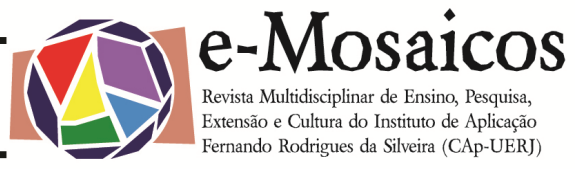

vários momentos da vida do sujeito. $\mathrm{E}$ então, por isso que nesse estudo que nós estamos desenvolvendo agora, a gente vai estudar como os estudantes do Ensino Fundamental, os mesmos estudantes... A proposta é que seja uma pesquisa de seis anos, mas nesse momento a gente tem proposto o que é chamado de primeira onda, que são os primeiros três anos, são alunos do sétimo, oitavo e nono anos, como que eles entendem a discriminação no cotidiano deles e se esses problemas de preconceito e discriminação se relacionam de alguma maneira com a aprendizagem deles. De fato nós sabemos que alguma relação existe. Porque tem uma pesquisa que nós estamos estudando passo a passo, tem um relatório de pesquisa encomendado pelo INEP sobre preconceito e discriminação no cotidiano das escolas. É uma pesquisa de larga escala feita com 5 mil sujeitos, quinhentas e tantas escolas, no qual a gente percebeu que os pesquisadores, que fizeram essas investigação, eles foram criando índices de percepção de preconceito e discriminação e um dos achados dessa pesquisa do INEP é que as escolas que tinham o maior índice de preconceito e discriminação, que tinham o maior índice entre os seus sujeitos, professores, alunos, pais, gestores, maior índice de distância social dos sujeitos de algumas categorias determinadas, que queriam mais distância em relação a negros, que queriam mais distância em relação a homossexuais, a ciganos, a deficientes físicos. As escolas que tinham o maior índice de percepção sobre problemas de bullying no cotidiano da escola, elas eram também as que tinham pior desempenho nas avaliações da Prova Brasil, que avalia português e matemática. A gente sabe que alguma relação existe entre escolas com um forte climade preconceito e discriminação e desempenho escolar, isso parece ser segundo esse relatório uma tendência. Então, a nossa pesquisa ela quer partir dessa descoberta e entender como se dá essa relação. Que implicações o preconceito e a discriminação afetam a aprendizagem? Por quê? Porque das nossas pesquisas anteriores muitas vezes os professores alegam que isso é um tema que não Ihes compete diretamente. Por exemplo, sou professor de matemática, preciso ensinar matemática, eu não deveria parar minha aula de matemática para tratar de um caso de racismo. Eu sou professor de ciência, de geografia ou de história e eu não me sinto preparado para resolver um problema de homofobia ou de machismo na minha sala de aula, porque tenho que dar conta do conteúdo de geografia, matemática, história e etc. Com esse dado, a gente está querendo dizer que os problemas de preconceito e discriminação sim, são problemas escolares, porque eles afetam diretamente o desempenho escolar dos sujeitos. Então, não deveria ser uma coisa alheia a nenhum professor, pensar, refletir, buscar estratégias pedagógicas para lidar com o preconceito e a discriminação na sala de aula. Então, essa é a nossa inspiração, ou elemento detonador, e a gente quer, ouvindo os alunos durante três anos, através de questionários, sobre a percepção deles, questionários que mostrem o desempenho cognitivo também de alguma maneira a gente vai tentar fazer isso. Isso está em processo de elaboração, tem que pensar um pouco sobre como faz isso. E também de entrevistas, a gente vai tentar ver como que esses sujeitos entendem como o preconceito e a discriminação se relacionam, pretendemos captar como que se dá essa relação. Nossa opção é por 11 escolas do ensino fundamental que estão em torno da universidade. São escolas públicas. A gente acredita até o momento que consiga localizar 800 sujeitos e eles serão acompanhados no $7^{\circ}$, $8^{\circ}, 9^{\circ}$ ano. A característica do estudo longitudinal é que não importa a série e nem o que acontece com o sujeito, na medida do possível se o sujeito mudar de escola, nós iremos atrás do sujeito, se o sujeito ficar reprovado, nós continuaremos a acompanhar o sujeito. Até para a gente perceber se a reprovação tem alguma relação com o tema que estamos estudando. 
e-Mosaicos - Revista Multidisciplinar de Ensino, Pesquisa, Extensão e Cultura do Instituto de Aplicação Fernando Rodrigues da Silveira (CAp-UERJ)

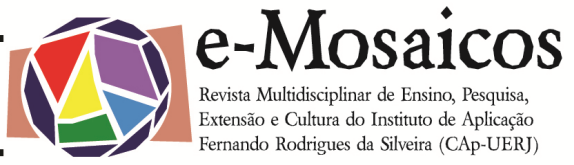

\section{HELENA ARAÚJO: E inicialmente os sujeitos são indicados pela escola, ou não?}

MARCELO ANDRADE: Não, a gente pretende pegar o universo. Então, nós vamos à escola $X$, a gente vai tentar saber qual é o universo dos alunos que estão no $7^{\circ}$ ano. São 40 ? São 80 ?

\section{HELENA ARAÚJO: Todas as escolas são com $7^{\circ}$ ano?}

MARCELO ANDRADE: Em todas as escolas nós iniciaremos com o $7^{\circ}$ ano. Em 2015 encontraremos os sujeitos no $7^{\circ}$ ano, em 2016 se $90 \%$ está no $8^{\circ}$ ano tudo bem, se $10 \%$ ou $5 \%$ continuam no $7^{\circ}$ nós continuaremos acompanhando os sujeitos que foram reprovados, que supostamente serão reprovados, a gente não sabe e os que passaram para $08^{\circ}$ ano, durante três anos nós vamos acompanhar os sujeitos que estão hoje matriculados no $7^{\circ}$ ano. Daqui a três anos vamos ver onde eles estão: se eles foram reprovados, se eles foram evadidos, se eles progrediram no sistema, como eles percebem o preconceito e a discriminação e como está o desempenho deles, por exemplo, em português, matemática e outros conteúdos. Então, o nosso objetivo é esse. Isso é possível fazer com tantos sujeitos porque agente vai fazer questionário, mas a proposta é que a gente entreviste até $10 \%$ desses sujeitos, então a ideia são 800 questionários por ano, 80 entrevistas por ano. Vamos fazer uma média...

\section{HELENA ARAÚJO: Então, na verdade vão ser 480 entrevistas ao longo dos seis anos.}

MARCELO ANDRADE: Ao longo dos seis anos, com os mesmos sujeitos, a gente vai sempre entrevistar os mesmos sujeitos. Os estudos longitudinais, eles se caracterizam por essa opção. Porque quando você faz a Prova Brasil, por exemplo, é uma avaliação de desempenho, você pega uma safra, se a gente puder fazer essa comparação de pessoas com safra, mas a Prova Brasil daqui a dois anos são outros sujeitos. Você compara, mas, na verdade, você fez a prova Brasil de 2007 com um grupo de pessoas e a de 2009 com outro grupo de pessoas, então, você compara pessoas diferentes, mas são pessoas que estavam terminando. Então, na verdade é uma comparação de larga escala possível, mas você não tem um acompanhamento dos sujeitos de 2007 até 2009. As pesquisas, desses estudos longitudinais, combinam com todos os outros estudos. Você precisa saber os dados de larga escala, você pode também fazer entrevistas mais individualizadas e você também pode fazer esses acompanhamentos mais ao longo do tempo. Então, essa pesquisa ocupa um espaço que eu acho que ainda, nas pesquisas educacionais, são poucas exploradas. A gente não vai fazer isso a nível nacional porque não temos grupo de pesquisa para isso. Nós vamos fazer em um estudo de caso, vamos dizer assim, que é uma região do Rio de Janeiro.

HELENA ARAÚJO: Eu faria uma pergunta agora, mais uma provocação que me ocorreu enquanto você estava falando: Se você acha que uma das hipóteses do impacto dos preconceitos nas aprendizagens, passa pelo rebaixamento da autoestima do sujeito? Essa é uma das hipóteses? Porque ela pode ser verdadeira ou não. Isso a gente vai ter que testar, mas você tem isso como uma das hipóteses? 
MARCELO ANDRADE: Eu acho, eu posso dizer que sim. Eu acho que não é apenas que o aluno fica com uma baixa autoestima. Não é só isso! Eu acho que, por um lado situações de preconceitos e discriminação podem fazer com que o clima escolar - vamos começar do contexto mais amplo - seja mais tenso, mais difícil deser levado, que eu tenha como aluno que colocar mais energia para fugir de situações de bullying, de perseguição, de discriminação, piadas, de agressões físicas muitas vezes. E eu então, não consiga muitas vezes colocar a minha energia naquilo que deveria ser, que é a aprendizagem. Então, isso é um pouco o clima. O próprio clima da escola pode ser ruim e pode prejudicara aprendizagem. Essa pode ser a primeira hipótese. A segunda hipótese pode ser também, pode ser não, eu acho que é: é que preconceitos e discriminação fazem com que nós tenhamos visões distorcidas sobre as pessoas! Então, eu acho que a gente já sabe disso por outras pesquisas, por outros estudos, que conforme a expectativa que se cria sobre a criança, você vai exigir mais ou menos. 0 professor - enquanto adulto-se ele tem, mesmo inconscientemente, um preconceito, uma discriminação contra crianças, sei lá, porque são negras, porque são faveladas, porque são de classes sociais mais baixas, então, ele cria uma baixa expectativa. Ora, se eu tenho uma baixa expectativa sobre a criança, eu vou exigir menos dela e vou esperar menos dela, então, o desempenho dela consequentemente será menor. Essa é uma segunda hipótese. Como os sujeitos adultos criam expectativas sobre as crianças e se essas expectativas estão atravessadas pelo preconceito e pela discriminação. Ah, essa menina é menina e para matemática a nota dela é boa, ou porque esse jovem é homossexual, ele não vai estudar mesmo, ele vai virar sei lá ... um travesti, uma travesti. Então, eu não preciso me preocupar com o estudo dela. Esses preconceitos podem criar expectativas baixas dos professores sobre os alunos. Uma outra hipótese é essa que você está dizendo. A própria autoestima da criança, já que ela sofre o preconceito, tem que colocar a energia dela em resolver as situações de preconceito e discriminação que ela enfrenta no cotidiano e ainda tem uma baixa expectativa sobre o seu desempenho, que ela acabe se adaptando a essa baixa expectativa e tendo sobre ela mesma uma autoestima afetada sobre o desempenho dela. Então, a gente não sabe que elemento conta mais: se é o elemento estrutural, mais do efeito que a sociedade tem sobre aquela identidade, ou se é a coisa mais local, institucional como que a escola criou, ou não criou, um clima favorável para resolver esse problema e para facilitar a aprendizagem? Se for um problema de expectativa que o professor tem sobre a criança, ou se essa criança já incorporou uma baixa expectativa sobre ela mesma? Eu não saberia te responder, mas acho que essas hipóteses estão num conjunto de hipóteses para entender porque situações de preconceito e discriminações afetam a aprendizagem. A gente está apostando, não por nada, mas pela pesquisa anterior do INEP, que sim, há uma relação. Como essa relação se dá é que vai ser nosso esforço.

HELENA ARAÚJO: E fora toda nossa experiência em sala de aula, todos nós somos professores, a linha de pesquisa que você coordena - além de fazer parte do grande GECEC, coordenado pela professora Vera Candau -, todos nós somos professores de diferentes disciplinas e temos por sabedoria da nossa vivência docente, ver isto acontecer em sala de aula.

MARCELO ANDRADE: Sim. E as pesquisas que a gente tem feito até agora, que a gente também tem feito pesquisas qualitativas com gruposde professores, com grupos de alunos, com entrevistas, com elementos focais. Isso indica também, mas nós não podemos afirmar que isso perdura ao longo do tempo, isso a gente não sabe afirmar ainda. Mas, por exemplo, na pesquisa que a gente fez com um grupo de professores, o tema da "Intolerância religiosa atrapalha a aprendizagem?", a gente descobriu que sim, não só a pesquisa que foi feita pelo 
Pedro Teixeira (ex-orientando de Marcelo Andrade de Doutorado), por exemplo, mas por outros professores. Quando a gente pega a pesquisa da Raquel Pinho (orientanda de doutorado de Marcelo Andrade), que pesquisou a questão da homofobia e também do Felipe Bastos (ex-orientando de mestrado de Marcelo Andrade), por exemplo, agente vê que tanto os professores como os alunos indicam que o tema da homofobia atrapalha o tema ligado à aprendizagem. A gente só pode afirmar isso para aquele grupo de professores, que nós entrevistamos e para aquele grupo de alunos, que nós trabalhamos. Agora a gente está tentando ver com um grupo maior e ao longo do tempo.

HELENA ARAÚJO: E Marcelo, então ... está claro, a gente percebe a importância do estudo dessa temática, a contemporaneidade, a urgência desse tema dentro das escolas, quer sejam públicas ou particulares e imagina, não só brasileiras, mas no mundo todo! Como é que você acha que a escola pode combater a questão do preconceito?

MARCELO ANDRADE: Eu acho que a primeira coisa que eu mais percebo, intuitivamente, dessas pesquisas que a gente fez e também com a formação continuada de professores, que a gente tem feito, é que o professor perceba que este fenômeno está dentro da escola, que pertence à sua sala de aula. Porque muitas vezes o professor, ele tenta... Não é raro agente entrevistar gestores de escolas ou professores no começo da entrevista é assim: nessa escola não tem preconceito, nessa escola agente trata todo mundo igual, nessa escola... Quer dizer, uma coisa é a intencionalidade do professor e do gestor, mas numa sociedade racista, eu acho que é improvável, e o relatório FIPE vai mostrar isso, que o racismo não esteja também dentro da escola. Numa sociedade machista, ou então, a gente não acredita que a sociedade brasileira é machista. Aí, a gente já partiu de premissas que não são verdadeiras. Acreditando que estamos em uma sociedade machista, por tudo que nós sabemos, então, o machismo estará dentro da escola. A expectativa sobre as meninas, aí tem uma grande contradição porque as meninas acabam tendo melhor desempenho que os meninos, mas também tem a ver com o sistema de códigos simbólicos que dá papéis diferenciados para meninas e meninos, permitindo aos meninos mais subversão e às meninas mais submissão etc. Então, se você está numa sociedade homofóbica, que as dificuldades coma temática das sexualidades diversas, então, isso vai estar na escola. A primeira contribuição que podemos dar à escola, é que a escola reconheça que esse é um tema da nossa sociedade. $E$ que sendo um tema da nossa sociedade está dentro da escola e dentro da sua sala de aula. Esse seria o primeiro ponto: a não negação do problema.

HELENA ARAÚJO: E nisso eu também emendaria a nossa próxima pergunta para você que é: qual seria, ou deve ser, o papel dos professores dentro dessa escola no combate aos preconceitos?

MARCELO ANDRADE: Então, eu acho que o papel do professor, primeiro ele deveria fazer um exercício de reconhecimento. Estou partindo da afirmação anterior. $\mathrm{E}$ ao reconhecer, não negar a necessidade de uma intervenção pedagógica. Então, o que a gente tem escutado dos professores é que quando se reconhece, porque primeiro é isso: primeiro tem que reconhecer; quando se reconhece, eu não sei lidar com isso. Isso é uma questão que tem que vir da educação familiar. A minha obrigação é ensinar e não educar. Essa é uma frase quea gente escuta muito: Que eu tenho que ensinar. O que ele quer dizer com isso? Que ele tem 
que ensinar o conteúdo de história ou de geografia, ou de matemática ou de português? E parece que esse conteúdo não tem relação com esses problemas, ou que ele é o especialista dos conteúdos e não das relações sociais. Então, eu acho que o professor deveria reconhecer, estar atento para poder reconhecer, reconhecer que aquilo é uma questão, intervir pedagogicamente seja em sala de aula no momento, seja em projetos mais amplos, seja com a ajuda da coordenação pedagógica, da orientação educacional, da gestão da escola em casos específicos. A gente também tem que dizer quea gente tem encontrado relatos, principalmente de coordenadores pedagógicos e orientadores educacionais, que são aqueles mais responsáveis por esses casos, que vão e conversam com o agressor, com o agredido, com a turma, com o professor. E eles vão tentando solucionar. Mas isso, em minha opinião, não deve ser uma preocupaçãosó desses gestores pedagógicos educacionais. Tem que ser de todos os profissionaisdesdeo cara que abre o portão até à pessoa que faz a limpeza da escola. Então, todos tem que estar sensíveis a essa temática e saber que isso é um problema, que éum problema sério que traz sofrimento e luto para muitas pessoas. $E$ que não só isso, que isso interfere diretamentena missão que eles pensam ser a prioritária, que é a do ensino deconteúdos. Quando a gente conseguir mostrar para os professores que isso afeta diretamente a aprendizagem dos conteúdos, eu acho que, na minha humilde opinião, ele vai entender que isso também faz parte do seu trabalho. Isso é conteúdo, também. Talvez, não seja um conteúdo específico, sei lá, da tabela periódica, não é a Revolução Francesa, não éa equação de segundo grau. Mas é um conteúdo porque as pessoas se relacionam e se essas relações estiverem mais harmonizadas, vamos dizer assim, esses outros conteúdos específicos, que parecem ser só esses a preocupaçãodos professores, eles fluirão, eles serão melhor construídos, eles serão melhor difundidos, como a gente quiser chamar, conforme a concepção do professor no desenvolvimento cognitivo dos estudantes.

\section{HELENA ARAÚJO: Marcelo tá claro, claríssimo, e junto a isso como você vê o papel das famílias, nessa parceria com a escola, nesse combate aos preconceitos? Qual seria o papel das famílias?}

MARCELO ANDRADE: Olha, eu acho que primeiro a gentetem que conhecer as famílias. Eu acho que não vou falar nenhuma novidade, mas sabemos que hoje há muitas configurações familiares, né? Então, eu acho que talvez a primeira coisa que devamos fazer na escola é reconhecer que há diversas configurações familiares e valorizá-las igualmente. A gente sempre fica esperando que quando falamos, vamos chamar a família para uma parceria, você fica imaginando que virá papai e mamãe e seus filhos. Virão papai e mamãe que tem a sua prole, mas virá também a avó que cuida dos filhos, a mãe que cuida dos filhos, virão as duas mães, os dois pais. Esses são sempre os casos mais polêmicos, que as pessoas ficam com mais recusa de aceitar, mas eu até tento fugir desses exemplos, para ver que pode vir a avó que cuida da criança, pode vir a tia que cuida da criança, pode vir a mãe solteira, o pai que adotou, ou o pai viúvo, ou a mãe viúva. Então, você tem uma série de configurações familiares e que você vai ter que entender, que essa diversidade de famílias, com $\mathrm{S}$ bem puxado no plural mesmo, é essa diversidade de famílias que vai poder dialogar com a escola. Então, você já reconhecendo essa diversidade, talvez você consiga mostrar que - como diria Hanna Arent,- "a diversidade é a regra do mundo". Então, se a gente incorporar essa regra, que a diversidade é a regra do mundo, a pluralidade é a regra do mundo, você acho que fica mais fácil admitir que não exista um padrão, uma norma que deve ser respondida. Então, eu acho que a família tem queestar presente. Eu acho que nós nãotemos sido muito eficientes nesses diálogos com as famílias, na maioria das vezes. A gente já sabe disso. Não estou falando nenhuma novidade. Que as famílias são chamadas muitas vezes para falar de problemas, ou 
para dizer que o menino está mal comportado, ou para dizer que a família tem que participar mais. Então, eu acho que a gente tem que ter um diálogo, de ouvir quais são as demandas das famílias, de trazer as famílias para dentro da escola realmente como parceiras assumindo alguns dos processos pedagógicos.

HELENA ARAÚJO: É. Eu percebo, Marcelo, que normalmente a família é chamada mais, quando é para uma culpabilização por algum problema e não para ações mais preventivas, ou ações parceiras de combate no presente. Essa lógica tem que ser mudada.

MARCELO ANDRADE: Estou completamente de acordo. É isso que eu estou querendo dizer, que não devemos chamar somente a família na escola para falar dos problemas. Você não tem que chamar a família na escola só para falar de problemas, tem que chamar a família sempre. E para que ela assuma atividades que os familiares possam achar interessante. Eu acho que isso é mais fácil na educação infantil. Vai se tornando mais difícil com os anos do ensino fundamental e no ensino médio não tem mais o que fazer.

HELENA ARAÚJO: Parece que tanto os professores, quanto as famílias, se descompatibilizaram das funções de educadores, de certa forma.

MARCELO ANDRADE: É. Eu sempre levantouma hipótese que não sei até que ponto eu posso apoiar. Mas eu acho o seguinte: que a escola, como a gente sabe, não é umainstituição que existiu sempre. Ela é uma instituição inventada historicamente. Quando a gente inventa a instituição escolar, quea gente diz que tem um especialista, que somos nós os professores, para ensino de conteúdos específicos; eu acho que a gente não estava prevendo historicamente - duzentos, duzentos e tantos anos atrás -, que isso desembocaria num efeito colateral, que eu chamo de efeito colateral não previsto, que é a desautorização dos pais para o ensino. Você está dizendo para os pais que eles não são capazes de ensinar. Então, muitas vezes, e a gente tem dados de pesquisa sobre isso, de orientadores pedagógicos de âmbitos educacionais, que relatam que os pais vão até eles e falam assim: "Olha, você precisa me ajudar, porque eu não sei lidar com esse menino. Eu não sei lidar com meu filho. Ele é muito difícil. Eu não sei lidar com ele. Ele não me ouve." Porque o pai vai buscar a escola? Masa escola fala eu só ensino, quem educa é a família." Quando a gente tirou a função de ensinar as habilidades específicas, técnicas, do trabalho, do mundo, da vida, do mundo do trabalho, principalmente, das famílias, a gente de alguma maneira provocou um efeito colateral, que não estava previsto, que a família se sente desautorizada e ela não sabe como fazer. $E$ isso ela não sabe como fazer porque o mundo muda de geração para geração e porque ela (a família) acredita muito nessa instituição que é a escolar. Só que aí chega na escola e os professores falam "Minha função não é educar. A minha função é..." Essa separação que eu acho que não existe, entre educação e ensino, está muito presente no senso comum dos professores e a gente precisa quebrar isso. Não existe ensino sem a dimensão educativa também.

HELENA ARAÚJO: Com certeza! Marcelo, eu acho que essa sua fala final, da gente precisar quebrar com isso, eu concordo plenamente que educação e ensino tem que andar juntos. Tem que ter, na verdade, o mesmo sentido e significado, mas 
não é isso que a gente vê na maior parte das vezes. A minha última pergunta para te fazer, eu acho que de certa forma você já respondeu. Seria: qual conselho você daria aos professores frente a este mundo contemporâneo onde cada vez mais a gente tem que enfrentar as questões depreconceito, quer dentro da escola, querem outrosespaços educativos não formais? É...Você acho que já falou bastante coisa, mas não sei se você quer acrescentar mais alguma coisa para a gente então, finalizar a nossa entrevista.

MARCELO ANDRADE: Olha, eu acho que eu daria, não sei se posso chamar de dicas, mas algumas orientações. Primeiro reconhecer que, nós estamos em uma sociedade plural. Eu acho que esse é o primeiro reconhecimento. Estamos numa sociedade muito diversa na qual nós encontraremos opiniões, identidades, religiões, posicionamentos políticos, condições, orientações sexuais diferentes e, às vezes, divergentes das nossas próprias. Então, essereconhecimento, o professor como um profissional que está sempre em relação com os outros sujeitos - com jovens e crianças -, ele deve reconhecer. Uma segunda orientação é que possivelmente por nós estarmos numa sociedade, vou voltar a afirmar machista, racista, classista, homofóbica, com modelo de padrão de consumo etc, possivelmentenós também teremos um desses preconceitos. Então, acho que o professor tem que fazer um exercício quase que pessoal, não estou falando de terapêutico, mas dele com ele mesmo, auto reflexivo, dele reconhecer que possivelmente ele tenha algum desses preconceitos, em maior ou menor grau, mas é possível que ele tenha. Porque ele é um ser social que vive nessa sociedade, que tem seus próprios preconceitos. Então, reconhecer os seus próprios preconceitos. Se eu não reconheço, eu não trabalho. É igual um paciente com um diagnóstico, se eu não sei que estou com uma doença, eu não a trato, eu não a combato, não tomo as providências. Então, reconhecer queeu sou fruto dessa sociedade, que eu posso melhorar, entregar para as novas gerações uma escola e uma sociedade melhor do que a que eu encontrei. Então, acho que reconhecer a pluralidade, reconhecer que o preconceito é uma realidade nessa sociedade. Reconhecer que eu faço parte dessa sociedade, por isso tenho preconceito, seria uma boa dica. Eu acho que uma outra dica é tentar ver coletivamente como que nós podemos responder, no cotidiano da escola, com projetos pedagógicos a atividades que nos ajudem a entender, conhecer, aceitar, trabalhar e a superar preconceitos e discriminações. Acho que a gente não tem outro caminho. No entanto, infelizmente, eu acho que a gente vê hoje, na nossa sociedade brasileira, o endurecimento, o enrijecimento de posturas identitárias que levam as pessoas a ficarem mais fechadas nas suas próprias identidades e não se colocarem em diálogo. Então, se eu sou de postura política $X$, não dialogo com $Y$, porque eles pensam diferentes. Se eu sou da religião $A$, eu não quero conviver, nem estudar determinados assuntos porque achoque isso agride minha identidade religiosa. Se eu tenho orientação sexual $X$, eu não quero... Isso é o que diz o relatório. Eu estou colocando aqui $X$ e $Y$, mas a gente sabe de quem está falando. São as religiões afro-brasileiras as mais atacadas, são as orientações sexuais homoafetivas as mais atacadas, são as pessoas de cor da pele não brancas as mais atacadas, são as mulheres as mais atacadas, mais violentadas. Então, acho que é preciso a gente estar aberto para essa pluralidade, que é a nossa sociedade. E que agente possa sinceramente, como professores e como adultos, deixar como legado para essas gerações que nós estamos educando, um mundo aonde isso seja, não sei se menos evidente, mas um mundo onde preconceitos e discriminações provoquemmenos sofrimento. $E$ que a gente possa colocar para a frente todo mundo - seja com que cor da pele, com que sexualidade, com que religião, com que classe social - para que as pessoas aprendam e por elas mesmas possam encontrar os caminhos que elas considerem os mais adequados. Eu acho que eu diriapara finalizar, isso! 
e-Mosaicos - Revista Multidisciplinar de Ensino, Pesquisa, Extensão e Cultura do Instituto de Aplicação Fernando Rodrigues da Silveira (CAp-UERJ) v. 5 - N. 9 - JUNHO 2016 - ISSN: 2316-9303

HELENA ARAÚJO: Nossa! Muito obrigado, foi maravilhoso, temos só a agradecer!

MARCELO ANDRADE: Eu que agradeço. 